\title{
Hempseeds (Cannabis spp.) as a source of functional food ingredients, prebiotics and phytosterols
}

\author{
Sergey V. Grigoryev ${ }^{1}$, Ksenia V. Illarionova ${ }^{2}$ and Tatiana V. Shelenga ${ }^{1}$ \\ ${ }^{1}$ N.I. Vavilov Institute of Plant Genetic Resources, 42-44 Bolshaya Morskaya, St. Petersburg, 190000, Russia \\ ${ }^{2}$ Peter the Great St. Petersburg Polytechnic University, Polytechnicheskaya, 29, St. Petersburg, 195251, Russia \\ e-mail: ser.grig@mail.ru
}

\begin{abstract}
The history of agriculture gives evidence that hemp had been cultivated by farmers for seed and oil near the northern limit of agriculture since ancient times. Nowadays, hemp is a focus of interest as a source of prebiotics as functional food ingredient. This study was aimed at evaluating physiologically active metabolomic compounds in the seed of thirty-three Cannabis spp. accessions, representing industrial dual-purpose (fibre and seed), universal, breeding materials used for food, ruderal and recreational landraces grown in Northwestern Russia. The content of polyunsaturated fatty acids, polysaccharides, polyhydric alcohols, phytosterols and phytol in seeds were measured. The maximum concentration of linoleic acid reached 43794 ppm, linolenic acid 4277, oleic acid 17112, polysaccharides 131113 , polyhydric alcohols 21384 , and sitosterol 793. Ruderal hemp was found to be rich in phytol ( $35 \mathrm{ppm})$. The food seed/oil material contained the maximum amounts of campesterol and sitosterol. The studied hemp accessions can serve as sources of physiologically active and safe ingredients of healthy food and phytosterols as well as be used in breeding programs to develop hemp seed cultivars.
\end{abstract}

Key words: industrial hemp, polyhydric alcohols, polyunsaturated fatty acids, sitosterol, campesterol, phytol

\section{Introduction}

Cannabis originated in Eurasia, in the Northern Temperate Zone, where low-THC gene pools and their hybrids, termed "hemp" and assignable to C. sativa L. subsp. sativa var. sativa (European Hemp = Cannabis Group European Fibre and Oilseed), were produced (Small 2018). In Europe, hemp was grown not exclusively for fibre, but also for its edible seed and oil, especially in the northern part of the continent. Hemp plants were used as drugs, both for medical and recreational purposes. Feral hemp (or "Ditch Weed" in the USA), termed as "hemp weed" (C. ruderalis Janisch.), supplied hempseed oil in parts of the former USSR (Vaughan 1970). The previous century's history of industrial agriculture gives evidence that hemp seed cultivars were successfully grown near the northern border of agriculture in Europe ( $66^{\circ} \mathrm{N}$, approx.) for seed and oil of high nutritional value (Grigoryev 2005, Grigoryev et al. 2019). Hemp cultivation at high latitudes was considered to promote the high antioxidant capacity and nutritional quality of its seed and oil (Blade et al. 2005). The industrial cultivar USO 11 was recommended for cultivation in Finland as an early-maturing variety (Sankari and Mela 1998). Other cultivars, such as USO 31, Beniko and Bialobrzeskie, were evaluated as suitable for the long-day growth conditions prevailing in Finland (Sankari 2000). Mostly hemp fibre was the focus of attention. Nevertheless, there was an increasing interest in total exploitation of the plant with the intention of using seeds, fibre and shives (Kymäläinen et al. 2001). In Europe, the area cultivated with industrial hemp (dual-purpose production: seed and stem) increased from 15700 ha in 2013 to 33000 ha in 2016, with a further increase expected, mainly driven by the rising demand for hemp seed (Baldini et al. 2020).

A number of modern studies suggest that hemp for seed could become a promising food crop because of its high nutritive traits and antioxidant potential (Irakli et al. 2019). Hemp seeds and oil have started to be used in a variety of food products. Hemp-based food products are considered to be less allergenic than those made from other edible seeds (Mamone et al. 2019). Hemp seeds exert beneficial effects and attract attention as a potential func tional food (Frassinetti et al. 2018).

The term "functional foods" was defined as whole foods along with fortified, enriched, or enhanced foods that have a potentially beneficial effect on health when consumed as part of a varied diet on a regular basis at effective levels based on significant standards of evidence. Some food ingredients may cause health benefits. Food containing such components was called functional. Scientific functional food research must effectively establish the bioavailability and efficacy of these components (Crowe and Francis 2013). Functional food is referred to a group of products with high levels of functional food ingredients (FFIs) - physiologically active compounds, capable of reducing the risks of diseases related to nutrition. In addition to a number of other compounds, the list of FFIs 


\section{AGRICULTURAL AND FOOD SCIENCE}

S. V. Grigoryev et al. (2020) 29: 460-470

includes polyunsaturated fatty acids (PUFAs), plant sterols, polysaccharides, etc. Polyhydric alcohols are attributed to physiologically functional food ingredients (prebiotics), i.e. compounds or a set of compounds that provide beneficial effects on the human organism when systematically consumed with food, as a result of selective growth stimulation and/or bioactivity increase in normal intestinal microflora (State Standard 2005).

The potential of modulating the microbiome-gut-brain axis, and subsequently mental health, through the consumption of functional food and prebiotics, is an emerging and novel topic of interest. Functional foods have won popularity globally in recent years. Functional foods are popular in European countries like Finland, Sweden, the Netherlands and Poland (Özen et al. 2014).

Components of various diets, such as fruits, vegetables, oily fish, olive oil, and nuts, serve as a model for functional foods based on their natural nutraceuticals, including polyphenols, terpenoids, flavonoids, sterols, and unsaturated fatty acids (Alkhatib et al. 2017).

The effects of PUFAs on cardiometabolic health, such as $\alpha$-linolenic, linoleic, and oleic acids, have received much attention in past years (Li et al. 2018). These compounds probably act as antioxidants, protecting cell membranes from the negative impact of free radicals. Linoleic acids have multiple beneficial effects on human health, including anticarcinogenic, anti-inflammatory, anti-oxidative, and antipathogenic ones (Peng et al. 2018).

Safflower, maize, and sunflower seed oils are acknowledged as sources of PUFAs (Vahvaselkä and Laakso 2010). Linseed is also numbered among the discussed functional food sources due to the presence of omega- 6 (linoleic) and and omega-3 ( $\alpha$-linolenic) fatty acids, which are effective in reducing the risk of cardiovascular diseases, lowering the cholesterol level, and relaxing the arterial smooth muscle cells in arteries, thus enhancing the blood flow. Linseeds, however, contain antimetabolic compounds, such as linatine, phytic acids, protease inhibitors, and cyanogenic glycosides, which is a serious disadvantage. Clinical research has shown (Dzuvor et al. 2018) that the consumption of such compounds by man or livestock may lead to problems with assimilation of main nutrients, and various health complications. For safe utilization of flaxseeds for food or feed, these components should be removed or inactivated to physiologically undetectable limits (Roulard et al. 2017, Dzuvor et al. 2018).

Polysaccharides are valuable as dietary fibers (Slavin 2013). Hempseed polysaccharides protect intestinal epithelial cells from hydrogen peroxide-induced oxidative stress (Wen et al. 2019). Raffinose increases the relative abundance of probiotics, and decreased that of pathogenic bacteria, beneficially affecting the gut microflora, iron bioavailability, and brush border membrane functionality (Pacifici et al. 2017).

Plant- and food-derived sterols possess antioxidant, metabolic regulating, immunomodulatory, and anti-inflammatory properties. Also they are recognized as anticancer agents, suggesting their application strongly as an alternative therapy in some chronic diseases (Sánchez-Crisóstomo et al. 2019). Cereals, margarine, vegetables and vegetable oils were the main food sources of phytosterols (sitosterol, campesterol, stigmasterol, avenasterol, brassicasterols and stanols) in Finland (Valsta et al. 2004). The intake of total sterols was $305 \mathrm{mg} \mathrm{day}^{-1}$ for men and 237 $\mathrm{mg} \mathrm{day}^{-1}$ for women. Another study showed that phytosterol-enriched frankfurters and cold cuts as a part of habitual Finnish diet reduced the serum total cholesterol concentration in hypercholesterolemic subjects when the intake of sitosterols was $2.1 \mathrm{~g} \mathrm{day}^{-1}$, but not with a lower dose (Tapola et al. 2004). Myo-inositol reduces the risk of developing gestational diabetic mellitus in pregnancies (Guo et al. 2018).

The present research was aimed at determining the content of polyunsaturated fatty acids, polysaccharides, polyhydric alcohols, phytosterols and phytol in seeds of genetically diverse Cannabis accessions. The aim of the study is to understand the nutritional value of hempseeds.

\section{Materials and methods \\ Plant material, growth conditions and experimental setup}

The study involved 33 hemp (Cannabis spp.) accessions (Table 1), originated in northern and northwestern areas of Russia: Karelia, Komi Republic, Arkhangelsk, Kirov, Leningrad, Vologda and northeastern provinces (Grigoryev and Illarionova 2020). Besides, a number of early-ripening and cold-hardy accessions from Northern Kazakhstan, Ukraine and Armenia were analyzed (Grigoryev 2005). 
Table 1. Material for the research

\begin{tabular}{|c|c|c|c|}
\hline No & Catalogue number & Accession designation & Origin \\
\hline 1 & 151892 & Feral 1 & Northwestern Russia \\
\hline 2 & 151894 & Feral 2 & Northwestern Russia \\
\hline 3 & 151895 & Feral 3 & Northern Russia \\
\hline 4 & 149454 & Feral 4 & Northwestern Russia \\
\hline 5 & 149455 & Feral 6 & Northern Russia \\
\hline 6 & 149456 & Feral 7 & Northern Russia \\
\hline 7 & 149453 & Feral 8 & Northwestern Russia \\
\hline 8 & 151893 & Feral 12 & Northwestern Russia \\
\hline 9 & 596872 & Feral 25 & Armenia \\
\hline 10 & 590519 & Feral 57 & Northern Kazakhstan \\
\hline 11 & 151899 & Feral 58 & Northwestern Russia, Karelia \\
\hline 12 & 142365 & Feral AS & Northeastern Russia \\
\hline 13 & 149457 & Dual 08 & Northwestern Russia \\
\hline 14 & 149458 & Dual 6 & Northwestern Russia \\
\hline 15 & 149459 & Dual 8 & Northwestern Russia \\
\hline 16 & 142362 & Dual 16 & Northeastern Russia \\
\hline 17 & 142366 & Dual SL & Northeastern Russia \\
\hline 18 & 142368 & Dual UK & Northeastern Russia \\
\hline 19 & 142370 & Dual ZE & Northeastern Russia \\
\hline 20 & 142371 & Dual VE & Northeastern Russia \\
\hline 21 & 142373 & Dual PA & Northeastern Russia \\
\hline 22 & 142374 & Dual KR & Northeastern Russia \\
\hline 23 & 142375 & Dual DN & Northeastern Russia \\
\hline 24 & 142378 & Dual 41 & Northeastern Russia \\
\hline 25 & 142365 & Dual 37 & Northeastern Russia \\
\hline 26 & 595690 & Univ 10 & Ukraine \\
\hline 27 & 142310 & Univ 13 & Northeastern Russia \\
\hline 28 & 151896 & Recr 1 & Northwestern Russia \\
\hline 29 & 151897 & Recr 2 & Northwestern Russia \\
\hline 30 & 151898 & Recr 3 & Northwestern Russia \\
\hline 32 & 159129 & Minim 1 & Northwestern Russia \\
\hline 32 & 159130 & Minim 2 & Northwestern Russia \\
\hline 33 & 159129 & Minim 3 & Northwestern Russia \\
\hline
\end{tabular}

The accessions belonged to five different groups. The first group included 12 accessions of ruderal (or feral) hemp (Cannabis ruderalis Janisch. $=$ C. sativa subsp. spontanea Serebr.). Twelve accessions of this group were designated for the purposes in this study as "Feral". The specific feature of the plants in this group is the seed, medium-sized or small, enclosed in the hooded bracteole, which is occasionally hairy on the outer surface and may be up to $1 \mathrm{~cm}$ long, including the raised hilum. The seed has a protuberant hilum at the base and variegated seed surface color (mosaic pattern). Accessions in the $2 \mathrm{nd}$ and $3 \mathrm{rd}$ groups represented breeding material of industrial hemp types (C. sativa L.). The 2 nd group included 13 accessions of dual-purpose utilization (fibre and seed), designated as "Dual". The 3rd group consisted of two accessions of universal use (fibre, seed and oil), designated as "Univ". Three accessions in the 4th group, designated as "Recr.", are recreational landraces (Small 2018). These accessions had been used by local population for various medicinal and/or recreational purposes. Seeds are small and/or medium in size, variously colored. The 5th group incorporated three accessions of $C$. sativa, designated as "Minim." which represented breeding material of industrial hemp grown for food (seed and oil). Characteristic features of this group are medium-sized or relatively large seeds, usually naked, with hooded bracteoles almost absent or as small as possible; their pericarp (seed coat) extremely thin, relatively soft, light-colored, without a mosaic pattern on the surface. The beak (basal protuberance) is absent or contrastingly minimized. 


\section{AGRICULTURAL AND FOOD SCIENCE}

S. V. Grigoryev et al. (2020) 29: 460-470

Seeds were grown out from the hemp accessions in 2017-2018 at Pushkin and Pavlovsk Laboratories of VIR $\left(59^{\circ} 40^{\prime} 16^{\prime \prime} \mathrm{N} 30^{\circ} 24^{\prime} 15^{\prime \prime} \mathrm{E}\right)$ under the soil and climate conditions of the Russian Northwest (a subzone of the boreal forest zone), with a climate transiting from the marine to the mildly continental one, characterized by abrupt daily temperature fluctuations, weather instability, cloudiness, excessive and spatially irregular rainfall. The hottest month was July, with its mean air temperature $+16.4^{\circ} \mathrm{C}$, and maximum $+33^{\circ} \mathrm{C}$. Agrometeorological conditions in the years of experiments did not reliably differ from the long-term mean values. Mean monthly temperatures during the growing season of hemp plants varied from $+10^{\circ} \mathrm{C}$ in May to $+17.8^{\circ} \mathrm{C}$ in July; precipitation from $42 \mathrm{~mm}$ in May up to $78 \mathrm{~mm}$ in August. Soils in the experimental fields were soddy-podzolic on drift clays, improved to a medium level. The gross content of nitrogen was up to $0.2 \%$, phosphorus $0.12-0.13 \%$, and potassium $1.5 \%$. The field experiment was performed in randomized blocks, with three replications. Each year the accessions were sown into the soil on May 15, using one-row plots, $7 \mathrm{~m}$ long, with $45 \mathrm{~cm}$ between rows, and $20 \mathrm{~cm}$ between plants in a row. During the growing season, no mineral fertilizers were applied to the soil. Seeds were hand-harvested from the plants on September 5, as soon as they ripened in the second half of inflorescences. An aggregate seed sample was collected from all plants of each accession. The harvested seeds underwent passive drying for three months in a special drying room at $+20^{\circ} \mathrm{C}$ and a relative air humidity of $16-18 \%$, and then transferred to the biochemistry lab. All operations, including seeding, crop management, harvesting, postharvest drying and biochemical analyses, were performed in the shortest time possible, simultaneously for all accessions in order to equalize temporal and accidental variations of traits in line with the principle "all else unchanged" (ceteris paribus).

\section{Analytical procedures}

Preparation of samples and biochemical analysis

The harvested seeds were weighed and homogenized with corresponding amounts of methanol in the ratio 1:10. Each sample was infused for 30 days at $5-6{ }^{\circ} \mathrm{C}$, the resulting extract centrifuged at $14000 \mathrm{rpm}$ for $10 \mathrm{~min}$, and 100 $\mu \mathrm{l}$ of the extract evaporated on a CentriVap Concentrator (Labconco, USA). After adding $50 \mu \mathrm{l}$ of Bis(trimethylsilyl)trifluoroacetamide (BSTFA) to the solid residue, it was exposed to $100{ }^{\circ} \mathrm{C}$ on Digi-Block (USA) for $40 \mathrm{~min}$. The analysis was performed on a capillary column: HP-5MS 5\% Phenyl Methylpolysiloxane (30.0 m, $250.0 \mu \mathrm{m}, 0.25$ $\mu \mathrm{m})$, employing gas-liquid chromatography coupled with mass spectrometry (GC-MS) on an Agilent 6850 chromatographer with a quadrupole mass analyzer (Agilent 5975B VL Mass-Selective Detector, Agilent Technologies, USA). The analysis was performed at $1.5 \mathrm{ml} \mathrm{min}{ }^{-1}$ helium flow rate in the column, heating conditions from $+70^{\circ} \mathrm{C}$ up to $+220^{\circ} \mathrm{C}$ at $4{ }^{\circ} \mathrm{C} \mathrm{min}{ }^{-1}$, detector temperature $+250{ }^{\circ} \mathrm{C}$, injector temperature $+300^{\circ} \mathrm{C}$; sample volume $1 \mu \mathrm{l}$ and tricosane solution in pyridine $\left(1 \mu \mathrm{g} \mathrm{\mu l}^{-1}\right)$ as the internal standard were used. The deconvolution and metabolite identification data were processed with AMDIS (Automated Mass spectral Deconvolution and Identification System). A semi-quantitative assay of the metabolite profiles was performed by calculating the total ion peak areas with the internal standard method using the UniChrom software (New Analytical Systems, Belarus, www.unichrom. com) and NIST Version 2.0 Mass Spectral Library (National Institute of Standards and Technology, USA). The relative content of biochemical components is expressed in $\mathrm{ppm}\left(\mu \mathrm{g} \mathrm{g}^{-1}\right)$ in dry matter.

\section{Statistical analyses}

The results of the metabolomic analysis of hemp seeds were processed with STATISTICA 10 for Windows and MC Excel 2010. One-way analysis of variance was employed to identify statistically significant differences between hemp accessions and groups of accessions. Cluster analysis was performed.

\section{Results and discussion}

The average, minimum and maximum values of phytol, several polyunsaturated fatty acids (PUFAs), polysaccharides, and polyhydric alcohols are presented in Table 2 in ppm.

Among the compounds analyzed in seeds, polysaccharides discovered in highest amounts. Total polysaccharides reached 131113 ppm; among them, the highest content was of sucrose, varying in the range of 11516-96792 ppm, and raffinose (1022-31089 ppm). Maltose content varied within 32-547 ppm range. Among PUFAs contained in hemp seeds, linoleic acid had the highest content (up to 43794 ppm). Highest amounts of oleic and linolenic acids were 17112 and $4287 \mathrm{ppm}$, respectively. The content of total polyhydric alcohols in the seeds varied within the range of 1504-21384 ppm; among them, the maximum values were found for dulcitol, varying from 25 to 18302 ppm, and myo-inositol (88-6097 ppm). The mean content of sterols was 423.3 ppm, with the highest amounts of 


\section{AGRICULTURAL AND FOOD SCIENCE}

S. V. Grigoryev et al. (2020) 29: 460-470

sitosterol (178-793 ppm) and campesterol (39-295 ppm). Phytol content in the seed samples varied from 3.8 to the maximum of $34.6 \mathrm{ppm}$, thus making the mean of $13.2 \mathrm{ppm}$ (Table 2).

Table 2. The content of phytol, polyunsaturated fatty acids, polysaccharides and polyhydric alcohols in seeds of hemp (Cannabis spp.) accessions (ppm in dry matter), NW of Russia, 2017-2018*

\begin{tabular}{lllll}
\hline Biochemical compounds (PubChem CID:) & Average & Min. & Max. & SD \\
\hline Phytol (:5280435) & 13.2 & 3.8 & 34.6 & 9.7 \\
Linolenic acid (:5280934) & 1608 & 265.3 & 4287 & 11201 \\
Oleic acid (:445639) & 3021 & 765 & 17112 & 4929 \\
Linoleic acid (:5280450) & 8617 & 967 & 43794 & 12042 \\
Maltose (:6255) & 170.6 & 31.6 & 547.1 & 140.2 \\
Raffinose (:439242) & 15240 & 1023 & 31089 & 7586 \\
Sucrose (:5988) & 46692 & 11516 & 96792 & 22086 \\
Sum of polysaccharides & 62907 & 12992 & 131113 & 27739 \\
Campesterol (:173183) & 110.1 & 39.4 & 295.0 & 71.3 \\
Sitosterol (:222284) & 423.3 & 178.3 & 793.6 & 173.8 \\
Myo-inositol (:892) & 849.8 & 88.4 & 6097 & 1146 \\
Dulcitol (:11850) & 1470 & 24.5 & 18302 & 3972 \\
Total polyhydric alcohols & 4635 & 1503 & 21384 & 4517
\end{tabular}

Highest amounts of phytol were found in the seeds of recreational (up to $34.0 \mathrm{ppm}$ ) and feral hemp accessions (up to 16.0 ppm) (Fig. 1A). Phytol may be considered as a valuable drug candidate (Arnhold et al. 2002, Islam et al. 2015). However, the seeds where it was found in largest amounts (feral germplasm and recreational landraces) have a specific unpleasant bitterish taste, without nut flavor. As a rule, such seeds possess a protuberant hilum at the base, an expressed exocarp, and the perianth's fragments undetachable or hardly detachable from the seed in the process of threshing. These seed traits are characteristic of feral and non-food hemp. We assume that the said greenish colored morphological parts of the seeds have participated in photosynthesis and retained residues of chlorophyll. Phytol is a component of the chlorophyll molecular structure. It leads to the supposition that the oil from the seed of hemp cultivars not intended for food (seeds with prominent rostrum (beak) and exocarp, fragments of the perianth, and mosaic surface) is expressly green-colored, specifically flavored, and bitterish in taste because some seed parts (seed coat, rostrum and perianth fragments) contain residues of chlorophyll molecules. On the contrary, the seeds of hemp food oil and seed (with minimized seed coat/pericarp) have no basal protuberance; they are lightly straw-colored without any mosaic pattern, contain very small amounts of phytol (less than 4.0 ppm) (Fig. 1A) and have a pleasant nut-like flavor.

The group of hemp accessions for food seed and oil had the highest amount (up to $44000 \mathrm{ppm}$ ) of linoleic acid in their seeds (Fig.1B). The accessions used for fibre and oil production (dual purpose) also had an increased content of this acid (up to $7500 \mathrm{ppm}$ ). However, the entire cluster of feral, dual, universal and recreational accessions showed no differences among their seeds in linoleic acid content, which varied inside the cluster within 3500-7500 ppm and was significantly lower than in the seeds of the accessions intended for food purposes (seed and oil) (Fig. 1B).

Similarly, the seed accessions from the feral, dual and universal groups demonstrated no differences among themselves in the content of linolenic acid, which amounts varied within the range of $750-4250 \mathrm{ppm}$ (Fig. 1C). Linolenic acid content was significantly high in the seeds of accessions for food seed and oil production (up to $4250 \mathrm{ppm}$ ) and recreational landraces (up to $3200 \mathrm{ppm}$ ).

Accessions from the feral, dual, universal and recreational groups did not differ among themselves in the content of oleic acid in seeds, the mean value varying within the range of 500-2500 ppm (Fig. 1D). Higher amounts of oleic acid were observed in dual-purpose accessions (up to $2500 \mathrm{ppm}$ ), and significantly high values in the accessions specialized for food seed and oil (up to $17500 \mathrm{ppm}$ ).

The highest amount of polysaccharides was registered in the seeds of recreational landraces: up to $130000 \mathrm{ppm}$, (Fig. 1H). It was significantly lower (ca. 80000 ppm) in the accessions for food seed and oil. Seeds from the feral, dual and universal groups showed no difference among themselves in total polysaccharides, their amount being 


\section{AGRICULTURAL AND FOOD SCIENCE}

significantly lower (up to 57000 ppm). Recreational landraces dominated in the content of sucrose (Fig. 1E), maltose (Fig. 1F) and raffinose (Fig. 1G). Raffinose content in food seed and oil accessions was minimal, comparable with that in the feral, dual and universal accessions (Fig. 1G).

A

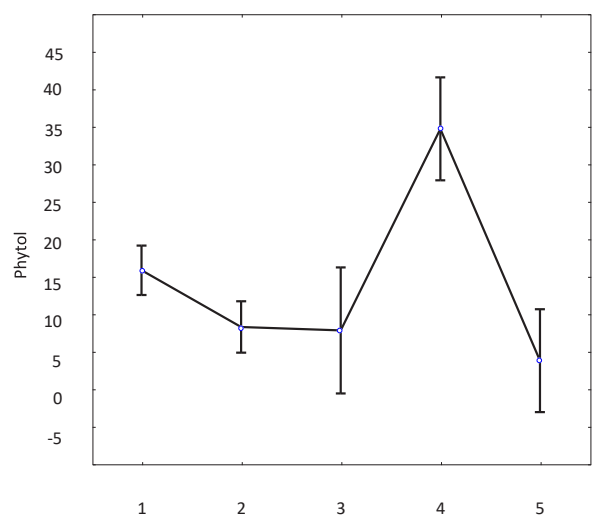

C

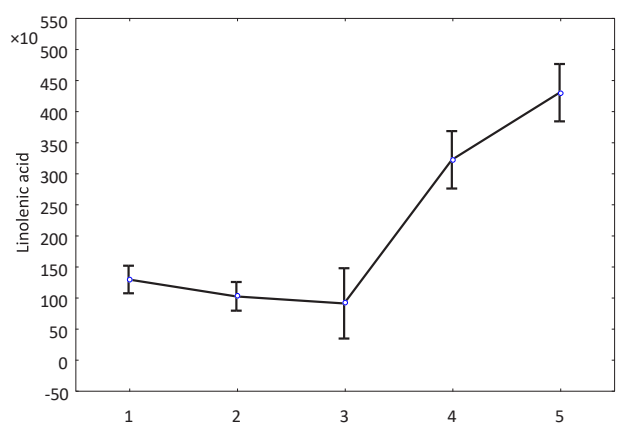

E
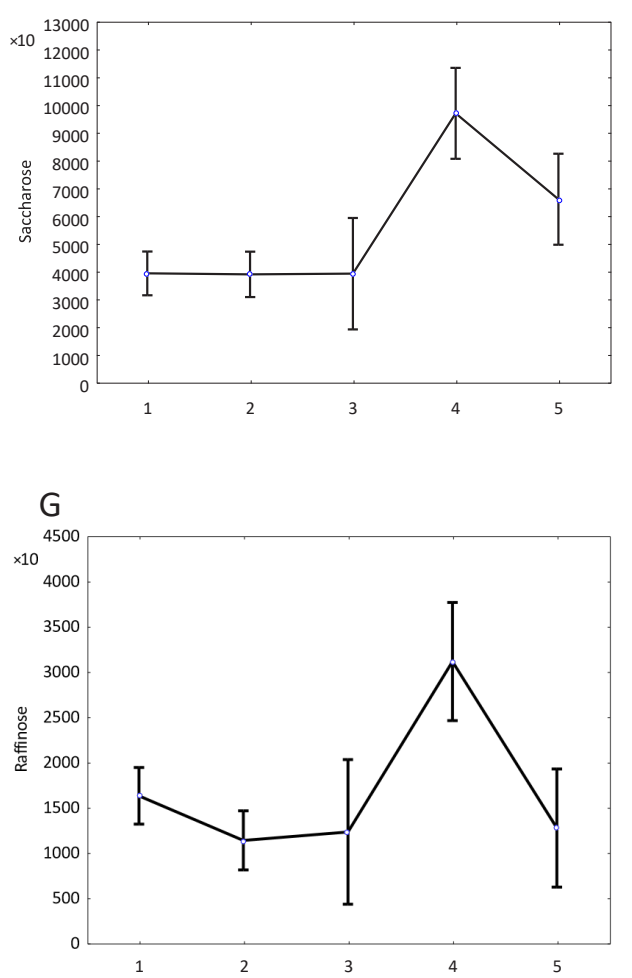

$\mathrm{B}$

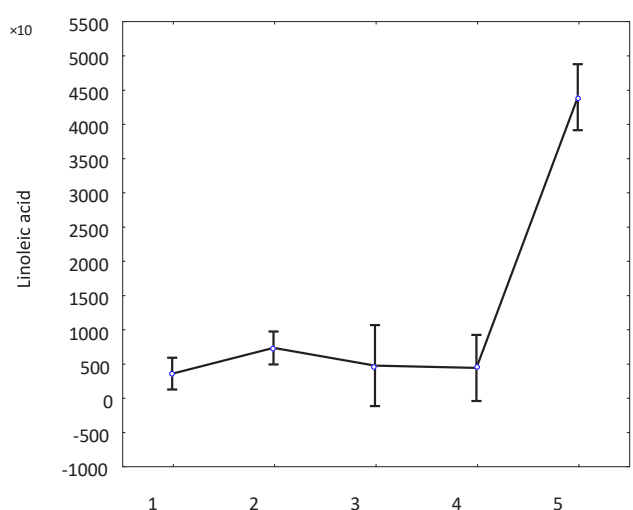

D

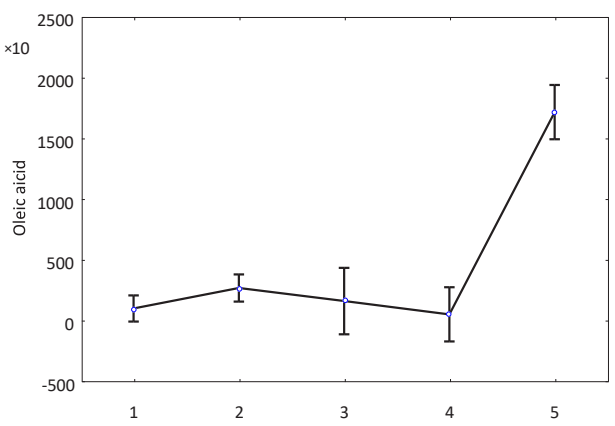

$\mathrm{F}$
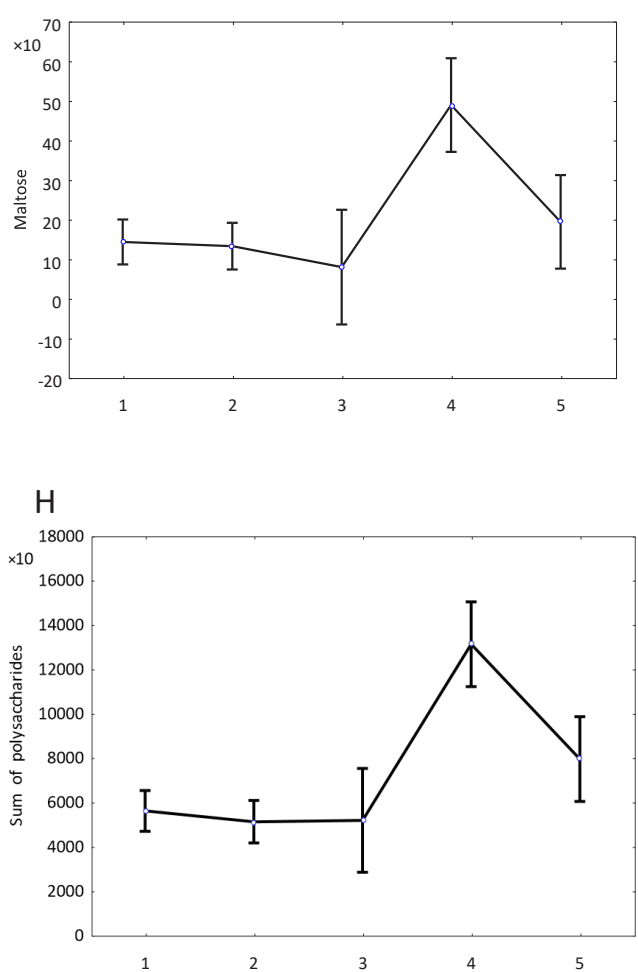

Fig. 1. Amounts of phytol, polyunsaturated fatty acids, and polysaccharides ( $\mathrm{ppm}$ in dry matter) in hemp seeds (Cannabis spp.) from different groups of accessions. (A) Phytol; (B) Linoleic acid; (C) Linolenic acid; (D) Oleic acid; (E) Sucrose; (F) Maltose; (G) Raffinose; (H) Total polysaccharides. Accession designations along X-axis: (1) Feral; (2) Dual use (fibre and seed); (3) Universal (fibre, oil and seed); (4) Recreational landraces; (5) Food seed and oil (minimized seed coat/pericarp). Means, vertical bars denote 0.95 confidence intervals. NW of Russia, 2017-2018 


\section{AGRICULTURAL AND FOOD SCIENCE}

S. V. Grigoryev et al. (2020) 29: 460-470

The sum of polyhydric alcohols was practically the same for all the studied groups (Fig. 2C). However, the level of myo-inositol was somewhat higher in recreational landraces (over 1500 ppm), while the lowest values (less than $250 \mathrm{ppm}$ ) were observed in universal accessions (Fig. 2B). Increased dulcitol content (up to $3000 \mathrm{ppm}$ ) was recorded for the seeds from the dual-purpose hemp group (Fig. 2A).

Significantly higher contents of sitosterol (ca. 800 ppm) (Fig. 2E) and campesterol (ca. 300 ppm) (Fig. 2D) were registered for the seeds of recreational landraces and accessions from the food seed and oil group. The seeds from the feral, dual and universal groups showed no notable values and did not differ among themselves in the content of phytosterols (sitosterol and campesterol).
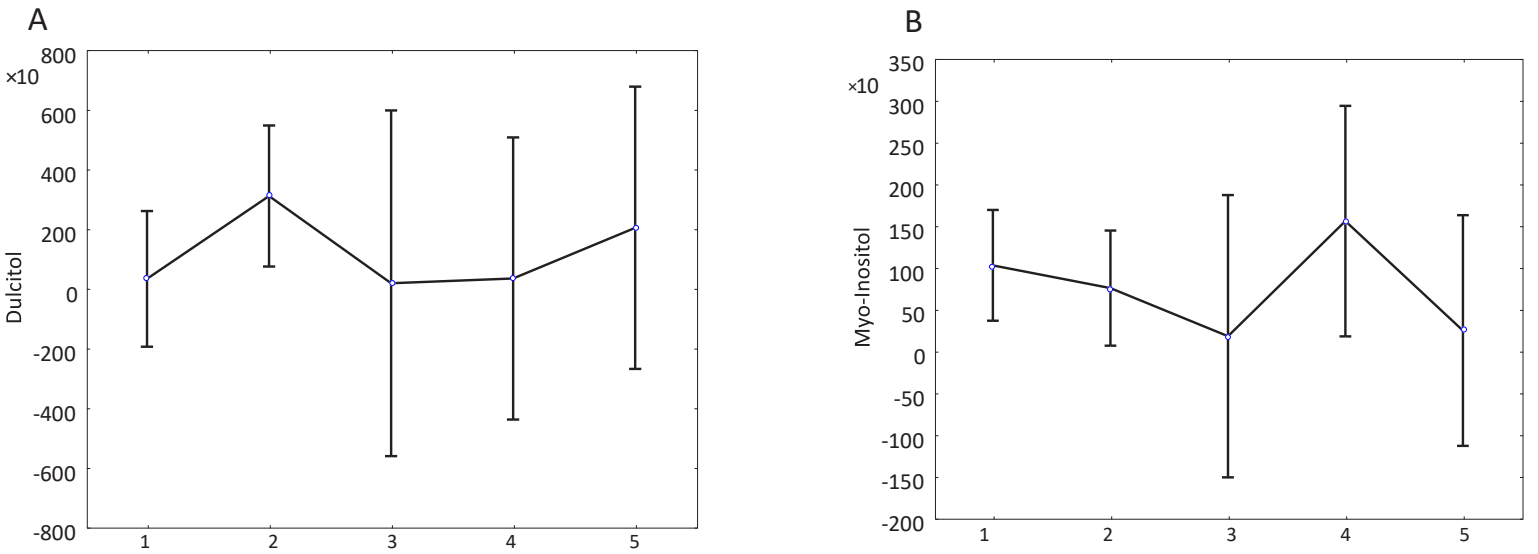

$$
\text { C }
$$
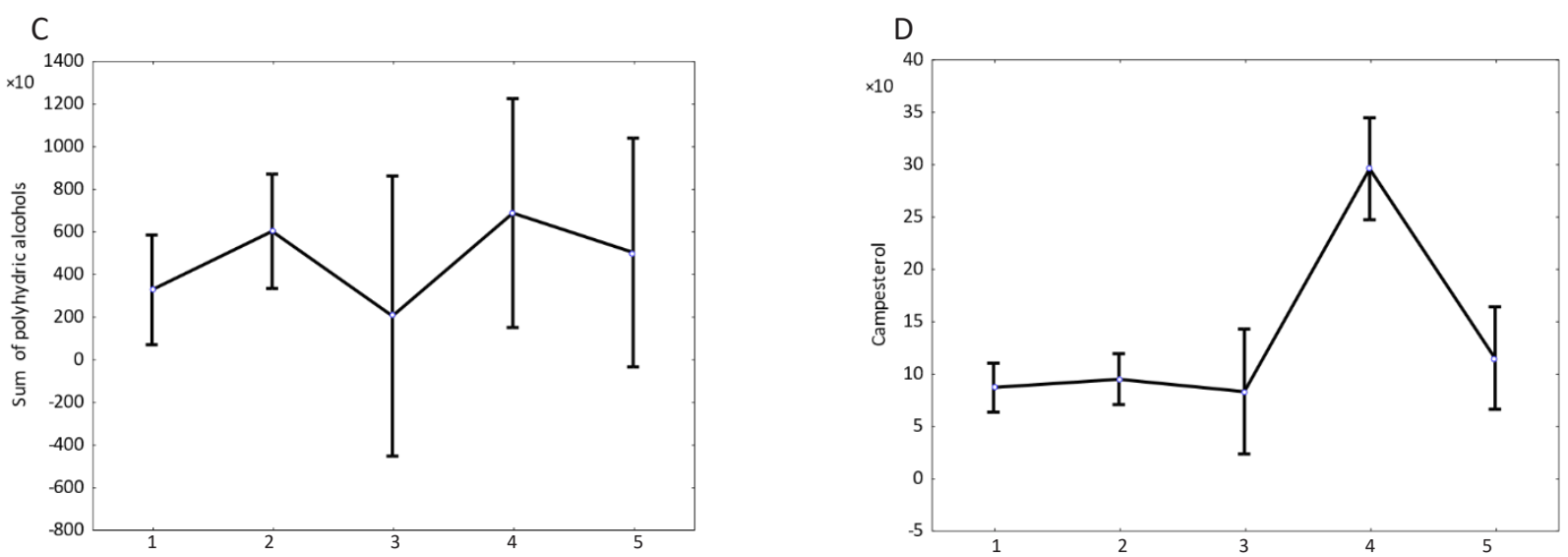

$\mathrm{E}$

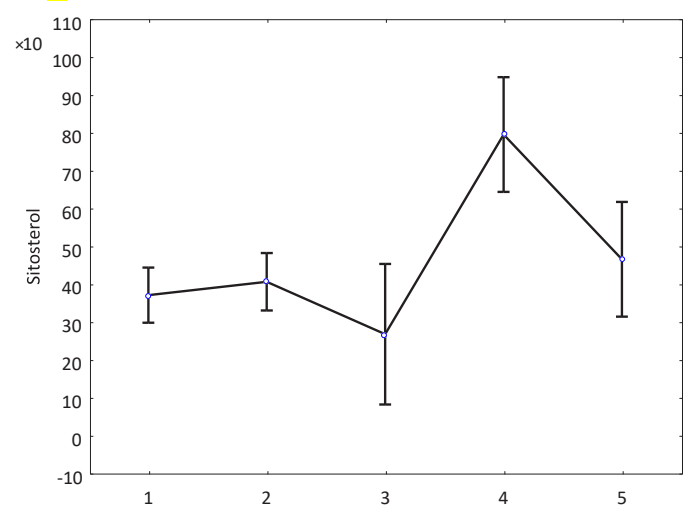

Fig. 2. Amounts of polyhydric alcohols and phytosterols (ppm in dry matter) in hemp seeds (Cannabis spp.) from different groups of accessions. (A) Dulcitol; (B) Myo-inositol; (C) Total polyhydric alcohols; (D) Campesterol; (E) Sitosterol. Accession designations along X-axis: (1) Feral; (2) Dual use (fibre and seed); (3) Universal (fibre, oil and seed); (4) Recreational landraces; (5) Food seed and oil (minimized seed coat/ pericarp). Means, vertical bars denote 0.95 confidence intervals. NW of Russia, 2017-2018

The tree clustering procedure for hemp accessions (amounts of phytol, PUFAs, polysaccharides and polyhydric alcohols in seeds) helped to identify six groups of diverse accessions - cluster A, B, C, D, E and F (Fig. 3). The group of hemp accessions from cluster $A$ was the remotest from clusters $E$ and $F$. The accessions from these clusters manifested significant differences in the discussed set of biochemical compounds in seeds. 


\section{AGRICULTURAL AND FOOD SCIENCE}

S. V. Grigoryev et al. (2020) 29: 460-470

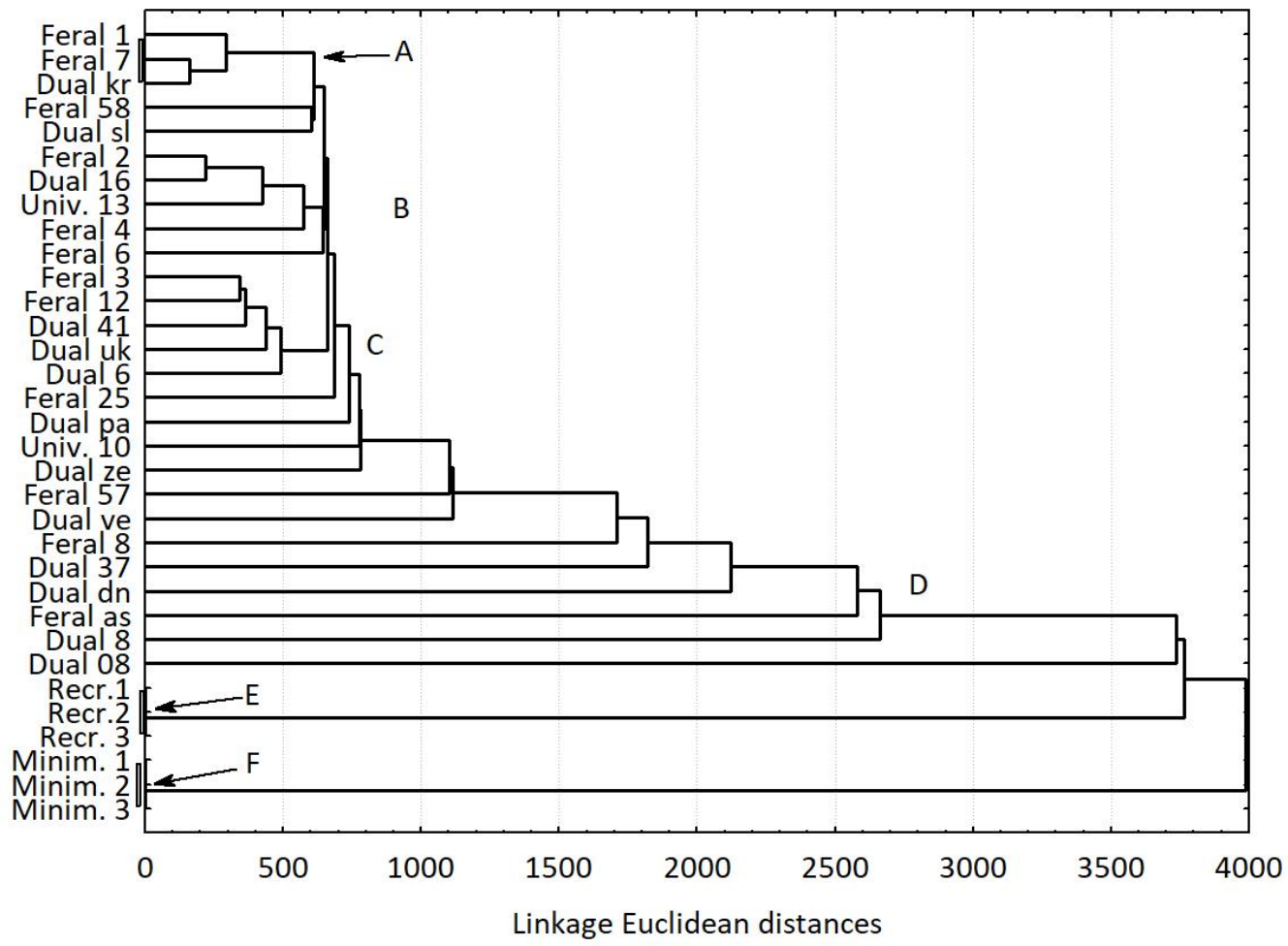

Fig. 3. Tree clustering of hemp accessions (Cannabis spp.) according to the amounts of phytol, polyunsaturated fatty acids, polysaccharides and polyhydric alcohols in seeds. Accession designations along Y-axis: (Feral...) Feral; (Dual...) Dual-purpose (fiber and seed); (Univ. ...) Universal (fibre, oil and seed); (Recr. ...) Recreational landraces; (Minim. ...) Food seed and oil (minimized seed coat/pericarp). (A); (B); (C); (D); (E); (F) Distanced clusters of assembled accessions

Cluster A predominantly harbored accessions conventionally designated as "Feral" (Fig. 3), i.e. representing ruderal hemp, and some accessions from the "Dual" group (industrial-type hemp for fibre and seed). The accessions united in cluster A were genotypically and phenotypically different, as industrial hemp is essentially different from ruderal hemp in the anatomy and morphology of a number of plant organs.

However, taking into account the biochemical composition of seeds for food purposes, they had similar features that grouped them in the same cluster A.

An analogous situation was observed with the accessions from clusters $E$ and $F$, which were situated side by side on the clustering tree and incorporated two different groups of accessions: recreational landraces (cluster E) and accessions from the food seed and oil group (cluster F). These accessions are quite unlike in a large number of anatomical, morphological and other traits as well as in the mode of utilization. However, biochemical properties of seeds of recreational landraces and food seed/oil accessions make them comparable and quite promising in terms of their value as functional food ingredients and prebiotics.

Thus, the accessions marked as "Feral" (ruderal hemp) and "Dual" (industrial types for fibre and seed) were united in one cluster $(A)$ and significantly distanced themselves from recreational landraces and food seed/oil accessions (clusters $\mathrm{E}$ and F, Fig. 3 ) in terms of food-specific biochemical composition.

Table 3 presents average values of functional food ingredients, prebiotics and phytosterols for seed samples from cluster $\mathrm{A}$ and for the distanced clusters $\mathrm{E}$ and $\mathrm{F}$.

Ruderal hemp and some of the "Dual" accessions (industrial types for fibre and seed) from cluster A showed relatively high phytol content (11.7 ppm) and significantly low levels of linoleic, linolenic and oleic acids (984$3408 \mathrm{ppm}$ ). This group of hemp accessions also contained minimum amounts of sucrose, maltose, campesterol, sitosterol and dulcitol in seeds, but their contents of raffinose and myo-inositol were significantly high (19524 ppm and 704 ppm, respectively). 


\section{AGRICULTURAL AND FOOD SCIENCE}

S. V. Grigoryev et al. (2020) 29: 460-470

Table 3. Amounts of functional food ingredients, prebiotics and phytosterols in seeds of hemp (Cannabis spp.) accessions (ppm in dry matter) united in cluster $\mathrm{A}$ and the distanced clusters $\mathrm{E}$ and $\mathrm{F}$

\begin{tabular}{lllllll}
\hline Biochemical compounds & \multicolumn{7}{c}{ Clusters } \\
& \multicolumn{2}{c}{ A } & \multicolumn{2}{c}{ E } & \multicolumn{2}{c}{ F } \\
\cline { 2 - 6 } & \multicolumn{2}{c}{ mostly feral germplasm } & recreational landraces & \multicolumn{2}{c}{$\begin{array}{r}\text { food seed/oil accessions with } \\
\text { minized seed coat }\end{array}$} \\
& Average & SE & Mean & SE & Average & SE \\
Phytol & 11.7 & 1.5 & 27.6 & 5.4 & 3.7 & 1.3 \\
Linoleic acid (omega-6) & 3408 & 829 & 6910 & 2084 & 43794 & 741 \\
Linolenic acid (omega-3) & 1061 & 99.1 & 2472 & 570.0 & 4287 & 114.4 \\
Oleic acid & 985 & 328.5 & 2225 & 1389 & 17112 & 379.2 \\
Sucrose & 32676 & 314.3 & 75473 & 16515 & 64859 & 363.1 \\
Maltose & 138.1 & 26.6 & 379.9 & 84.9 & 193.0 & 30.8 \\
Raffinose & 19524 & 812.9 & 23572 & 5872 & 12691 & 938 \\
Total polysaccharides & 52916 & 1132 & 101582 & 22895 & 79331 & 1306 \\
Campesterol & 81.0 & 6.0 & 240.6 & 42.4 & 114.1 & 6.9 \\
Sitosterol & 398.3 & 28.2 & 669 & 98.5 & 464.2 & 32.6 \\
Myo-Inositol & 704.8 & 102.8 & 1310 & 201.9 & 243.5 & 118.8 \\
Dulcitol & 179.8 & 35.6 & 4819 & 3481 & 2023 & 41.1 \\
Total polyhydric alcohols & 2234 & 178.0 & 10465 & 2823 & 4976 & 205.5 \\
\hline Level of significance $p=0.05$ & & & & & &
\end{tabular}

The accessions from cluster $\mathrm{F}$ (food seed/oil) were characterized by maximum amounts of linoleic, linolenic and oleic acids (43794, 4287 and 17112 ppm, respectively), and low phytol content (3.7 ppm). The accessions from the neighboring cluster E (recreational landraces) also had high levels of oleic acid and PUFAs (2225-6911 ppm), but their content of phytol was the highest $(27.6 \mathrm{ppm})$. It is clear from the data in Table 3 that the seeds of recreational hemp landraces and food seed/oil accessions (clusters $E$ and F) may become valuable sources of sucrose, maltose, raffinose and phytosterols (campesterol and sitosterol) as well as myo-inositol, dulcitol and other polyhydric alcohols.

\section{Conclusions}

The analyzed hemp seeds were found to contain polysaccharides in plenty, reaching in total $131113 \mathrm{ppm}$. Sucrose (up to $96792 \mathrm{ppm}$ in dry matter) and raffinose (up to $31089 \mathrm{ppm}$ ) prevailed among them. The content of total polyhydric alcohols reached $21384 \mathrm{ppm}$; among these, the levels of dulcitol (up to $18302 \mathrm{ppm}$ ) and myo-inositol (up to $6097 \mathrm{ppm}$ ) were the highest. Of plant sterols, sitosterol and campesterol were found (up to 793 and $295 \mathrm{ppm}$, respectively). The content of phytol reached $34.6 \mathrm{ppm}$. Linoleic acid had the highest content in seeds among all PUFAs (up to 43794 ppm). The maximums of oleic and linolenic acids were 17112 and 4287 ppm, respectively.

Phytol amounts were the highest in the seeds of feral hemp and recreational landraces. Their seeds have a rather unpleasant bitterish flavor; their hilum is usually protuberant, exocarp is well-expressed, and perianth's fragments are either undetachable or cannot be easily detached from the seed when threshed. Seeds of the specialized food seed/oil cultivars are lightly straw-colored, without a mosaic pattern, and contain low amounts of phytol (less than $3.0 \mathrm{ppm}$ ). In a number of cases, the seeds of industrial fiber hemp stand out for their content of linoleic (ca. 6000 ppm) and oleic (ca. $2500 \mathrm{ppm}$ ) acids, as well as for total polysaccharides (ca. $6000 \mathrm{ppm}$ ) and sitosterol (no more than $400 \mathrm{ppm}$ ). However, to produce maximum amounts of functional food ingredients, plant sterols and prebiotics, one should use the chemotypes of hemp specialized for production of these compounds (food seed/oil accessions), with their highest amounts of linoleic, linolenic and oleic acids (43794, 4287 and 17112 ppm, respectively). Such accessions (and also, in some cases, seeds of recreational landraces) may become valuable sources of sucrose, maltose, raffinose, phytosterols (campesterol and sitosterol), myo-inositol, dulcitol and other polyhydric alcohols. 


\section{AGRICULTURAL AND FOOD SCIENCE}

S. V. Grigoryev et al. (2020) 29: 460-470

The hemp cultivated under the conditions of northern agriculture for seed and other products is a source of functional food ingredients and prebiotics. Ruderal hemp (sometimes referred to as hemp weed, feral hemp or "Ditch Weed") is a weedy progeny of the hemp once cultivated in the field (on homestead plots). Unlike the cultivated hemp plants, this type of hemp has undergone adaptive, hereditarily fixed changes. Its seeds have become small, easily shed and wind-blown, and acquired morphological features (raised hilum) attractive to some insects. Accessions of ruderal hemp may serve as sources of earliness or cold tolerance to develop relevant cultivars, while its seeds are potential reservoirs of phytol or polysaccharides. However, it is specialized hemp accessions that should be considered, if the aim is to obtain functional food ingredients and prebiotic in significant amounts. In some few cases, accessions of industrial hemp (fibre, dual-purpose or universal hemp types) may combine high yield and fibre quality with food values of seed and oil. But such cases are far from being frequent, and should be regarded as exceptions. The seeds of industrial fibre hemp accessions are, as a rule, non-uniform in color, size and, most importantly, biochemical parameters determining oil quality, food value and taste of seeds. Universal hemp accessions (cultivars) should be recognized as having little value seed for food.

As a rule, when the task is to obtain cannabinoids from inflorescences, specialized vegetatively propagated hybrids are cultivated in greenhouses. In our study, the accessions of recreational hemp have been grown from seeds in the open ground. A number of such accessions may be promising as sources of linolenic acid, polysaccharides sitosterol and campesterol. However, an inevitable conclusion comes to mind that in order to obtain biologically valuable functional food ingredients and prebiotics it is possible to use seeds of specialized early-ripening and cold-tolerant hemp lines and cultivars, specifically designed to yield food seed and oil, free from any undesirable psychotropic effects.

\section{Acknowledgements}

Authors are deeply grateful to Dr. Timo T. Rantakaulio from The Finnish Landrace Association Maatiainen for cooperation and constructive suggestions during the development of this research work. Biochemical analysis of samples in present paper has been performed within the framework of the State Assignment № 0662-2019-0001 (oil and fibre crop: evaluation and enlarge of genotypic variability), AAA-A19-119013090159-5 commissioned to VIR.

\section{References}

Alkhatib, A., Tsang, C., Tiss, A., Bahorun, T., Arefanian, H., Barake, R., Khadir, A. \& Tuomilehto, J. 2017. Functional foods and lifestyle approaches for diabetes prevention and management. Nutrients 9: 1310. https://doi.org/10.3390/nu9121310

Arnhold, T., Elmazar, M.M. \& Nau, H. 2002. Prevention of vitamin A teratogenesis by phytol or phytanic acid results from reduced metabolism of retinol to the teratogenic metabolite, all-trans-retinoic acid. Toxicological Sciences 66: $274-82$. https://doi.org/10.1093/toxsci/66.2.274

Baldini, M., Ferfuia, C., Zuliani, F. \& Danuso, F. 2020. Suitability assessment of different hemp (Cannabis sativa L.) varieties to the cultivation environment. Industrial Crops and Products 143: 111860. https://doi.org/10.1016/j.indcrop.2019.111860

Blade, S.F., Ampong-Nyarko, K. \& Przybylski, R. 2005. Fatty acids and tocopherols profiles of industrial hemp cultivars grown in the high latitude prairie region of Canada. Journal of Industrial Hemp 10: 33-43. https://doi.org/10.1300/J237v10n02_04

Crowe, K.M. \& Francis, C. 2013. Position of the academy of nutrition and dietetics: functional foods. Journal of the Academy of Nutrition and Dietetics 113: 1096-1103. https://doi.org/10.1016/j.jand.2013.06.002

Dzuvor, C.K., Taylor, J., Acquah, C., Pan, S. \& Agyei, D. 2018. Bioprocessing of functional ingredients from flaxseed. Molecules 23: 2444. https://doi.org/10.3390/molecules23102444

Frassinetti, S., Moccia, E., Caltavuturo, L., Gabriele, M., Longo, V., Bellani, L., Giorgi, G. \& Giorgetti, L. 2018. Nutraceutical potential of hemp (Cannabis sativa L.) seeds and sprouts. Food Chemistry 262: 56-66. https://doi.org/10.1016/j.foodchem.2018.04.078

Grigoryev, S. 2005. Hemp of Russian northern regions as a source of spinning fibres. Journal of Industrial Hemp 10: $106-108$. https://doi.org/10.1300/J237v10n02_09

Grigoryev, S.V., Shelenga, T.V. \& Illarionova, K.V. 2019. Hempseed and cottonseed oils in the accessions from the VIR collection as sources of functional food ingredients. Proceedings on Applied Botany, Genetics and Breeding 180: 38-43. (in Russian). https://doi.org/10.30901/2227-8834-2019-2-38-43

Grigoryev, S.V. \& Illarionova, K.V. 2020. Evaluation of factors having an effect on cannabidiol amount in Cannabis sativa L. Sel'skokhozyaistvennaya Biologiya 55: 107-117. https://doi.org/10.15389/agrobiology.2020.1.107eng

Guo, X., Guo, S., Miao, Z., Li, Z. \& Zhang, H. 2018. Myo-inositol lowers the risk of developing gestational diabetic mellitus in pregnancies: A systematic review and meta-analysis of randomized controlled trials with trial sequential analysis. Journal of Diabetes and its Complications 32: 342-348. https://doi.org/ 10.1016/j.jdiacomp.2017.07.007

Irakli, M., Tsaliki, E., Kalivas, A., Kleisiaris, F., Sarrou, E. \& Cook, C.M. 2019. Effect of genotype and growing year on the nutritional, phytochemical, and antioxidant properties of industrial hemp (Cannabis sativa L.) seeds. Antioxidants 8: 491. https://doi.org/10.3390/antiox8100491 


\section{AGRICULTURAL AND FOOD SCIENCE}

S. V. Grigoryev et al. (2020) 29: 460-470

Islam, M.T., de Alencar, M.V., da Conceição Machado, K., de Carvalho Melo-Cavalcante, A.A., de Sousa, D.P. \& de Freitas, R.M. 2015. Phytol in a pharma-medico-stance. Chemico-Biological Interactions 240: 60-73.

https://doi.org/10.1016/j.cbi.2015.07.010

Kymäläinen, H.-R., Hautala, M., Kuisma, R. \& Pasila, A. 2001. Capillarity of flax/linseed (Linum usitatissimum L.) and fibre hemp (Cannabis sativa L.) straw fractions. Industrial Crops and Products 14: 41-50. https://doi.org/10.1016/S0926-6690(00)00087-X

Li, K., Sinclair, A., Zhao, F. \& Li, D. 2018. Uncommon fatty acids and cardiometabolic health. Nutrients 10: 1559. https://doi.org/10.3390/nu10101559

Mamone, G., Picariello, G., Ramondo, A., Nicolai, M.A. \& Ferranti, P. 2019. Production, digestibility and allergenicity of hemp (Cannabis sativa L.) protein isolates. Food Research International 115: 562-571. https://doi.org/10.1016/j.foodres.2018.09.017

Özen, A.E., del Mar Bibiloni, M., Pons, A. \& Tur, J.A. 2014. Consumption of functional foods in Europe; a systematic review. Nutrition Hospitalaria 29: 470-478. https://doi.org/10.3305/nh.2014.29.3.7148

Pacifici, S., Song, J., Zhang, C., Wang, Q., Glahn, R.P., Kolba, N. \& Tako, E. 2017. Intra amniotic administration of raffinose and stachyose affects the intestinal brush border functionality and alters gut microflora populations. Nutrients 9:304. https://doi.org/10.3390/nu9030304

Peng, M., Tabashsum, Z., Patel, P., Bernhardt, C. \& Biswas, D. 2018. Linoleic acids overproducing Lactobacillus casei limits growth survival, and virulence of Salmonella typhimurium and enterohaemorrhagic Escherichia coli. Frontiers in Microbiology 9: 26-63. https://doi.org/10.3389/fmicb.2018.02663

Roulard, R., Fontaine, J.X., Jamali, A., Cailleu, D., Tavernier, R., Guillot, X., Rhazi, L., Petit, E., Molinie, R. \& Mesnard, F. 2017. Use of qNMR for speciation of flaxseeds (Linum usitatissimum L.) and quantification of cyanogenic glycosides. Analytical and Bioanalytical Chemistry 409: 7011-7026. https://doi.org/10.1007/s00216-017-0637-7

Sánchez-Crisóstomo, I., Fernández-Martínez, E., Cariño-Cortés, R., Betanzos-Cabrera, G. \& Bobadilla-Lugo, R.A. 2019. Phytosterols and triterpenoids for prevention and treatment of metabolic- related liver diseases and hepatocellular carcinoma. Current Pharmaceutical Biotechnology 20: 197-214. https://doi.org/10.2174/1389201020666190219122357

Sankari, H.S. 2000. Comparison of bast fibre yield and mechanical fibre properties of hemp (Cannabis sativa L.) cultivars. Industrial Crops and Products 11: 73-84. https://doi.org/10.1016/S0926-6690(99)00038-2

Sankari, H.S. \& Mela, T.J.N. 1998. Plant development and stem yield of non-domestic fiber hemp (Cannabis sativa L.) cultivars in long-day growth conditions in Finland. Journal of Agronomy Crop Science 181: 153-159. https://doi.org/10.1111/j.1439-037X.1998.tb00411.x

Slavin, J. 2013. Fiber and prebiotics: mechanisms and health benefits. Nutrients 5:1417-1435. https://doi.org/10.3390/nu5041417

Small, E. 2018. Dwarf germplasm: the key to giant Cannabis hempseed and cannabinoid crops. Genetic Resources and Crop Evolution 65: 1071-1107. https://doi.org/10.1007/s10722-017-0597-y

State Standard 2005. State Standard GOST R 52349-2005. Foodstuffs. Functional foods. Terms and definitions. Standartinform. Moscow. p. 1-3. (in Russian).

Tapola, N.S., Lyyra, M.L., Karvonen, H.M., Uusitupa, M.I. \& Sarkkinen, E.S. 2004. The effect of meat products enriched with plant sterols and minerals on serum lipids and blood pressure. International Journal of Food Sciences and Nutrition 55: $389-97$. https://doi.org/10.1080/09637480400002842

Vahvaselkä, M. \& Laakso, S. 2010. Production of cis-9, trans-11-conjugated linoleic acid in camelina meal and okra by an oat-assisted microbial process. Journal of Agricultural and Food Chemistry 58: 2479-2482. https://doi.org/10.1021/jf903383x

Valsta, L.M., Lemström, A., Ovaskainen, M.L., Lampi, A.M., Toivo, J., Korhonen, T. \& Piironen, V. 2004. Estimation of plant sterol and cholesterol intake in Finland: quality of new values and their effect on intake. The British Journal of Nutrition 92: 671-678. https://doi.org/10.1079/BJN20041234

Vaughan, J.G. 1970. The structure and utilization of oil seeds. 11 New Fetter Lane, London EC4: Chapman and Hall Ltd. 279 p.

Wen, Z.S., Xue, R., Du, M., Tang, Z., Xiang, X.W., Zheng, B. \& Qu, Y.L. 2019. Hemp seed polysaccharides protect intestinal epithelial cells from hydrogen peroxide-induced oxidative stress. International Journal of Biological Macromolecules 135: $203-211$. https://doi.org/10.1016/j.ijbiomac.2019.05.082 